\title{
Sexualidade, saúde sexual e poder disciplinar no espaço escolar
}

\author{
Paulo Sergio Rodrigues de Paula*
}

\section{Resumo}

Este trabalho decorre de uma intervenção realizada entres os meses de agosto a outubro de 2016 numa escola estadual de segundo grau, localizada numa cidade de médio porto na Região do Vale do Paraíba, onde procuramos cartografar e mapear as vivências, as práticas, as relações entre os adolescentes e professores a respeito do tema sexualidade/saúde sexual e reprodutiva. Nesse sentido, compreendemos o ambiente escolar como redes de sujeitos (docentes, discentes, funcionários e outros sujeitos diversos que adentram esse território), nossa intenção foi problematizar os dispositivos disciplinares em relação à sexualidade e saúde sexual e reprodutiva, situando a questão no cotidiano escolar, cartografado a partir de observações realizadas ao longo da primeira fase dessa intervenção, compreendida por observações das rotinas escolares nos espaços comuns e conversas com a direção, coordenação pedagógica e professores. O método utilizado foi a cartografia, que se refere não a territórios, mas a campos de forças e relações que se desdobram no tempo, ao se debruçar sobre figurações históricas em movimento permanente, significadas a partir de determinados regimes de enunciação de poder e saber. A partir das observações e narrativas construídas no percurso cartográfico, vimos que questões de sexualidade e saúde sexual e reprodutiva no espaço escolar não se limitam a uma ação redutível ao indivíduo, mas sim como efeito de complexas produções e práticas discursivas que se materializam e circulam por entre territórios, que além de instituir modos de subjetivação hegemônicos, constituem os sujeitos a partir da delimitação de relações de poder.

Palavras-chave: Educação. Parâmetros Curriculares Nacionais. Poder disciplinar. Saúde sexual e reprodutiva.

* Psicólogo, doutor em Ciências Humanas pela UFSC/ Université de Reims Champagne-Ardenne. Docente do Programa de Pós-Graduação em Psicologia Educacional do UNIFIEO. sergiorodrhigues@gmail.com 


\section{Sexuality, sexual health and disciplinary power in the school space}

\section{Abstract}

This work stems from an intervention carried out between August and October 2016 in a state high school, located in a medium port city in the Vale do Paraiba region, where we try to map and map experiences, practices, relationships between adolescents and teachers on the topic of sexuality/sexual and reproductive health. In this sense, we understand the school environment as networks of subjects (teachers, students, employees and other diverse subjects who enter this territory), our intention was to problematize disciplinary devices in relation to sexuality and sexual and reproductive health, placing the issue in school daily life, carded from observations made throughout the first phase of this intervention, understood by observations of school routines in common spaces and conversations with direction, pedagogical coordination and teachers. The method used was cartography, which refers not to territories, but to fields of forces and relationships that unfold in time, when looking at historical figurations in permanent motion, meant from certain regimes of enunciation of power and knowledge. From the observations and narratives constructed in the cartographic course, we saw that issues of sexual and reproductive health in the school space are not limited to a reducible action to the individual, but as the effect of complex productions and discursive practices that materialize and circulate through territories, which, in addition to instituting hegemonic modes of subjectivation, constitute the subjects from the delimitation of power relations.

Keywords: Education, National Curriculum Parameters, Disciplinary Power, Sexual and Reproductive Health.

\section{Sexualidad, salud sexual y poder disciplinario en el espacio escolar}

\section{Resumen}

Este trabajo se deriva de una intervención llevada a cabo entre agosto y octubre de 2016 en una escuela secundaria estatal, ubicada en una ciudad portuaria mediana en la Región del Valle de Paraíba, donde tratamos de mapear y mapear experiencias, prácticas, relaciones entre adolescentes y profesores en el tema de la sexualidad/salud sexual y reproductiva. En este sentido, entendemos el entorno escolar como redes de asignaturas 
(profesores, estudiantes, empleados y otras materias diversas que entran en este territorio), nuestra intención era problematizar los dispositivos disciplinarios en relación con la sexualidad y salud sexual y reproductiva, colocando el tema en la vida cotidiana escolar, estampada a partir de observaciones realizadas a lo largo de la primera fase de esta intervención, entendida por observaciones de rutinas escolares en espacios comunes y conversaciones con dirección, coordinación pedagógica y profesores. El método utilizado fue la cartografía, que no se refiere a los territorios, sino a los campos de fuerzas y relaciones que se desarrollan en el tiempo, al mirar las figuraciones históricas en movimiento permanente, significadas a partir de ciertos esquemas de enunciación de poder y saber. A partir de las observaciones y narrativas construidas en la ruta cartográfica, vimos que las cuestiones de salud sexual y sexual y reproductiva en el espacio escolar no se limitan a una acción reducible para el individuo, sino como un efecto de producciones y prácticas complejas dimensionamiento discursivo y circulando a través de territorios que, además de instituir modos hegemónicos de sujetos, constituyen los sujetos de la delimitación de las relaciones de poder.

Palabras clave: Educación. Parámetros Nacionales del Currículo. Poder Disciplinario. Salud Sexual y Reproductiva.

\section{Introdução}

A Organização Mundial de Saúde (OMS) trata a sexualidade como um aspecto central do ser humano, presente durante toda a vida, cujas características e expressões envolvem fatores de ordem biológica, psicológica e social e são entendidas como inerente ao ser humano.

Sexualidade é um aspecto central do ser humano durante toda sua vida e abrange o sexo, as identidades e os papéis de gênero, orientação sexual, erotismo, prazer, intimidade e reprodução. A sexualidade é experimentada e expressada nos pensamentos, nas fantasias, nos desejos, na opinião, nas atitudes, nos valores, nos comportamentos, nas práticas, nos papéis e nos relacionamentos. Embora a sexualidade possa incluir todas estas dimensões, nem todas são sempre experimentadas ou expressadas. A sexualidade é influenciada pela interação de fatores biológicos, psicológicos, sociais, econômicos, políticos, cultural, éticos, legais, históricos, religiosos e espirituais (WORLD HEALTH ORGANIZATION, 2007). 
Para Louro (2000), a premissa de que todos nós vivemos nossos corpos universalmente da mesma maneira é equivocada, pois a vivência da sexualidade está implicada por marcadores históricos, sociais e culturais que direcionam para uma ampla gama de desdobramentos e possibilidades. Neste sentido, os fatores de ordem histórica, social e cultural são responsáveis pelo direcionamento do modo que esses estímulos são compreendidos e recebidos pelos adultos e reverberam nas respostas e atitudes de como indivíduos em desenvolvimento vivenciarão a sexualidade.

A escola se constitui num local estratégico de atenção à infância e à adolescência, sendo a segunda forma de socialização no desenvolvimento humano atual, depois da família. Nesse sentido, enquanto equipamento pedagógico-social, a escola tem o dever de promover a cidadania e dar condições sólidas para a construção de um ser autônomo, inclusive com relação à sexualidade. Entretanto, não é incomum que os educadores tenham dificuldade em lidar com esses eventos em seu cotidiano e adotem posturas variadas, conforme sua própria formação moral, religiosa ou familiar (MAIA; SPAZIANI, 2010).

De acordo com Foucault (2007), para se analisar as condições do jogo discursivo e os seus efeitos, são necessárias três decisões: interrogar a nossa vontade de verdade, abandonar a soberania do significante e restituir ao discurso o seu caráter de "acontecimento", sendo que:

[...] o acontecimento não é nem substância nem acidente, nem qualidade, nem processo; o acontecimento não é da ordem dos corpos. Entretanto, ele não é imaterial; é sempre no âmbito da materialidade que ele se efetiva que é efeito; ele possui seu lugar e consiste na relação, coexistência, recorte, acumulação, seleção de elementos materiais; não é ato nem a propriedade de um corpo (FOUCAULT, 2007, p. 57).

Importa a questão do sujeito em relação com a sua ética, constituindo-se por intermédio das práticas de si, em que a questão central é saber como o indivíduo constitui a si mesmo, como um 
sujeito moral de suas próprias ações na relação de si para consigo.

Este texto se refere a uma cartografia da primeira fase de uma intervenção sobre sexualidade e saúde sexual e reprodutiva, junto a estudantes de uma escola pública, de ambos os sexos, com idade entre 12 a 18 anos. Realizada por três técnicos em saúde (psicólogo, enfermeiro, agente comunitário de saúde) do Programa Municipal de IST/HIV/AIDS, num município de médio porte no interior do Estado de São Paulo, entre os meses de agosto e outubro de 2016, essa intervenção teve como objetivo inicial promover o conhecimento dos adolescentes sobre sexualidade e saúde sexual e reprodutiva com ênfase nas infecções sexualmente transmissíveis (IST). Entretanto, alguns acontecimentos reforçaram a definição histórica e cultural dos papéis sociais desempenhados pelos sexos que repercutem no processo de construção da noção de saúde e direitos sexuais e direitos reprodutivos, reafirmando a configuração das relações desiguais com base no gênero.

No caso da cultura brasileira e ocidental em geral, a sexualidade tem sido foco de orientações sociais repressivas tanto na esfera familiar quanto na pública, motivada pelas orientações de condutas de contenção e para evitar sua expressão pela religião, educação, polícia e principalmente da medicina, nos levando a problematizar as questões sobre poder disciplinar e seus possíveis efeitos sobre a educação em sexualidade e saúde sexual e reprodutiva no espaço escolar, na vida dos estudantes e nos posicionamentos dos profissionais.

Essa intervenção surgiu a partir de um convite da direção escolar e da coordenação pedagógica da escola, que trouxeram como queixa o incômodo que a unidade escolar estava passando devido à ocorrência de uma aluna ter sido "flagrada" no banheiro, mantendo relações sexuais com dois alunos. Segundo relato da diretora da escola, "todos os alunos estavam em polvorosa com o ocorrido", sendo necessária "uma intervenção imediata para acalmar os ânimos e fomentar a transmissão dos saberes sobre os riscos da sexualidade precoce como gravidez e doenças sexuais". 
Sendo a escola um dos principais espaços de vivência em sociedade para as crianças e adolescentes, esta pode vir a ser um local de grande reprodução e legitimação de desigualdades ao impor em suas práticas pedagógicas valores e comportamentos dominantes, reforçando vários tipos de estereótipos.

Ao sermos chamados como técnicos de saúde sexual e reprodutiva, a direção escolar acreditava que a oferta "deste tipo de informação, aliada a uma base familiar sólida" seriam a solução para os problemas que estavam enfrentando. Para além da demanda da escola a nós dirigida, e da intervenção desenvolvida, neste texto buscamos, a partir da cartografia, elaborar teoricamente observações de situações e fatos analisados antes na primeira fase dessa intervenção, os quais considero como acontecimento. Para Foucault (2008), o acontecimento não é estrutura, não é fixo e não depende do conteúdo do discurso, ou seja, se refere àquilo que remete a um momento anterior à delimitação de objetos que irão emergir nas formações discursivas. Segundo Vandresen (2014), acontecimento pode ser definido como "o próprio conjunto das condições que tornam um discurso possível. Condições essas que não são apenas regras internas ao discurso, mas também condições não-discursivas". O acontecimento discursivo seria, então, o arranjo de coisas (sejam elas discursivas ou não) que possibilita a emergência dos enunciados e o estabelecimento do discurso (VANDRESEN, 2014, p. 82).

\section{Sobre o método cartográfico}

Segundo Guattari “A existência não é dialética, não é representável. Mal se consegue vivê-la!” (GUATTARI, 1992, p. 66). Desse modo, para o autor é importante que se opte por uma escolha ética que busca apreender a subjetividade na sua dimensão de criatividade processual ou corremos o risco de objetificação, reificação e cientificização (GUATTARI, 1992, p. 24). O olhar cartográfico não pressupõe a separação entre objeto e sujeito configurando-os como categorias transcendentais, mas procura se flexionar sobre elementos e discursos históricos em permanente movimento, constituídos 
a partir de determinados regimes de enunciação. Nesse sentido, a análise cartográfica tem como foco central a produção política da subjetividade, cujas formas de resistências, modos de sujeição e assujeitamento e produção de corpos sexuais e morais estão implicados com os jogos de enunciação e verdades.

Passos e Benevides (2009, p. 17) no intuito de descentrar o sujeito na hierarquia da produção de conhecimento, propõem uma reversão etimológica do método (metá $=$ reflexão, raciocínio, verdade e hódos = caminho, direção). Segundo os autores: "a reversão, então, afirma um hódosmetá. Desse modo, a diretriz cartográfica se faz por pistas que orientam o percurso da pesquisa, sempre considerando os efeitos do processo do pesquisador sobre o objeto da pesquisa, o pesquisador e seus resultados".

A cartografia aqui apresentada possui características de rizoma, conceituadas por Deleuze e Guattari (2011), como sendo desordenada, horizontal, conectável e em constante mudança, ou seja, mistura sujeito e objeto na constituição de novos modos de subjetivação, construindo e produzindo teorias e ações e de forma dinâmica e conjunta. O rizoma se caracteriza, portanto, por uma rede sem hierarquias, que entrelaçam, se absorvem e não possuem começo nem fim. O rizoma se encontra sempre no meio, entre as coisas, produzindo novos e múltiplos agenciamentos, podendo "derivar infinitamente, estabelecendo conexões transversais sem que se possa centrá-lo ou cercá-lo" (GUATTARI \& ROLNIK, 1986, p. 322).

Segundo Hashizume e Telles Jr. (2019), existem inúmeras entradas e produções de sentido para a experimentação cartográfica, pois esta "reinventa a metodologia de pesquisa, propondo movimentos: funções de dispositivos no método da cartografia, que colaboram na construção da referência, explicitação e transformação da realidade" (HASHIZUME, TELLES JUNIOR, 2019, p. 12). Assim sendo, o olhar cartográfico sobre sexualidade e saúde sexual/reprodutiva no espaço escolar parte do pressuposto de que a subjetividade pode ser constantemente (re)criada e (re)inventada, num processo que não busca modelos explicativos, mas sim, na 
problematização da constituição do sujeito no "entre forças" do campo social (KASTRUP, 2009).

\section{Acontecimento 1: moralidade ou a escola é laica, mas a direção da escola é religiosa}

Atualmente, o Brasil é considerado o maior país católico do mundo em número absoluto de fiéis. Historicamente, o catolicismo chegou aqui em 1500, mesmo ano do descobrimento do Brasil. Por herança da colonização portuguesa, o catolicismo foi a religião oficial do país desde a sua primeira Constituição, em 1824, até 1890, quando a liberdade religiosa foi instituída por decreto, o que passou a constar nas Constituições brasileiras a partir de 1891 (BUSIN, 2011).

A laicidade é um dos princípios dos Estados Modernos, por exemplo, o Brasil. Fruto da separação entre Estado e igreja, que foi excluída do poder político e administrativo e, em particular, do ensino, o Estado laico nasceu de um longo processo de laicização, de uma emancipação e construção progressiva, através de um afastamento dos dogmas, do clero e, sobretudo, do poder da Igreja Católica, ganhando vulto sob o influxo da Reforma Protestante, da filosofia de Rousseau, do Iluminismo, apenas para citar alguns exemplos (DOMINGOS, 2008).

Isso posto, qual não foi a nossa surpresa ao adentrarmos no espaço escolar no primeiro dia de intervenção? Alunas e alunos estavam no pátio escolar rezando o "Pai Nosso". Ao questionar o coordenador pedagógico sobre essa situação, ele nos respondeu que sempre rezavam antes de iniciar as atividades escolares. Iríamos iniciar uma intervenção com jovens a respeito do tema sexualidade e afins e fomos recepcionados com oração da Igreja Católica. O Estado não é laico? Pergunto ao coordenador, que prontamente responde:

\section{- O estado é laico, mas a direção da escola é religiosa!}

Esse acontecimento é muito significativo, pois fomos chamados para falar/formar justamente sobre sexo/sexualidade, um tema que há séculos as sociedades ocidentais têm produzindo sa- 
beres e poderes, e que sobretudo, nas sociedades cristãs, tornou-se algo que era necessário examinar, vigiar, confessar e transformar em discurso, tornando a confissão e o exame da consciência, num modo de colocar a sexualidade no centro da existência. A sexualidade se tornou objeto de investimentos, cuja proliferação discursiva na atualidade abrange não apenas sujeitos e grupos, mas também instituições diversas como escolas e igrejas, produzindo relações de saber-poder a partir de diferentes estratégias (FOUCAULT, 1984).

Assim sendo, os saberes e poderes do cristianismo acerca da sexualidade estão calcados no campo da moral sexual em que o ato sexual está associado ao mal e ao pecado; concebendo a conjugalidade monogâmica com finalidade procriadora; exaltando, rigorosamente, a castidade permanente e a virgindade (FOUCAULT, 1984, p. 17).

Podemos entender a moral como "um conjunto de valores e regras de ação propostas aos indivíduos e aos grupos por intermédio de aparelhos prescritivos diversos" (FOUCAULT, 1984, p. 26) que, por serem transmitidas de forma difusa, permitem escapatórias e anulação de certos pontos, e cujo conjunto prescritivo pode-se chamar de código moral. A moral foi tomada como um "comportamento real dos indivíduos em relação às regras e valores que lhe são propostos", ou seja, modos como os sujeitos se submetem, obedecem ou resistem, respeitam ou negligenciam certas prescrições (FOUCAULT, 1984, p. 26).

A respeito da repressão sexual, esta não é somente objeto de teoria, já que "vem acompanhada pela ênfase de um discurso destinado a dizer a verdade sobre o sexo" (FOUCAULT, 1988, p. 13). É acerca de uma história da sexualidade que impõe à Europa um período de repressão proveniente do modo de ligação entre poder, saber e sexualidade, que Foucault chamou de hipótese repressiva, na qual o autor recusa a imagem do poder como meramente opressor e contesta essa hipótese de que a sexualidade é reprimida, procurando mostrar que não existe silêncio e, ao contrário de uma repressão à sexualidade, o que aconteceu e ainda acontece é uma explosão discursiva da sexualidade. 
A demanda inicial da escola que nos levou a desenvolver intervenções sobre sexualidade e saúde sexual e reprodutiva corrobora com a hipótese repressiva, pois os fatos mostram que não ocorreram silenciamentos em torno do sexo, mas sim a proliferação de discursos de perspectivas individuais ou coletivas, tornando claro o fato das sociedades modernas "terem condenado o sexo a permanecer na obscuridade" e ao mesmo tempo "terem-se devotado a falar dele sempre, valorizando-o com o segredo" (FOUCAULT, 1988).

Desde a criação e adoção do Estatuto da Criança e do Adolescente (ECA, 1990), entre as diretrizes adotadas no Brasil, está o dever da sociedade e do Estado garantir que esses sujeitos exerçam sua cidadania e seus direitos livres de quaisquer formas de violência. Assim, tal qual foram caracterizados os direitos sexuais e reprodutivos da população adulta a partir das conferências internacionais de População e Desenvolvimento e da Mulher, respectivamente realizadas no Cairo, em 1994, e em Pequim, em 1995, os direitos sexuais e reprodutivos de crianças e adolescentes são também direitos humanos (BRASIL, 2005).

Ao instituir uma oração católica no início das atividades escolares e não ser questionada por coordenadores pedagógicos, funcionários e professores, a escola reverbera a compreensão de como o poder e os desejos se articulam, uma vez que a imagem do poder repressor da liberdade é que nos permite aceitar sua vigência e ao mesmo tempo questioná-la, seja por intermédio de discursos, seja por meio de práticas de resistência, como os jovens que mantiveram relações sexuais no templo escolar.

Nesse contexto escolar em específico, em relação à equipe técnica (coordenação pedagógica, direção, docentes), optou-se por chamar agentes externos para intervir, imperando um suposto silenciamento, resistências e dificuldades de abordagem, que reforçados pelo discurso religioso, impediram as educadoras de levarem a discussão até a sala de aula, relegando a tabu as questões referentes aos aspectos motivacionais, comportamentais e psicológicos envolvidos com as práticas sexuais e relacionais dos adolescentes. 


\section{Acontecimento 2: as limitações pessoais e didáti- co-pedagógicas}

Nas últimas décadas, concepções, práticas e políticas da sexualidade passaram por profundas transformações sociais, alterando e criando formas de relacionamentos e de estilo de vida, reverberando no modo de os adolescentes vivenciarem a sexualidade, que nessa etapa é manifestada por múltiplas identificações que envolvem a aceitação da própria imagem corporal, a descoberta do outro como elemento de amor ou desejo, do encontrar-se e das relações com os familiares, grupos e profissionais (ROMERO et al., 2007), sendo necessárias realizações de intervenções que contribuam para a promoção de uma vida sexual saudável. A saúde sexual pode ser definida como a:

[...] habilidade de mulheres e homens para desfrutar e expressar sua sexualidade, sem risco de doenças sexualmente transmissíveis, gestações não desejadas, coerção, violência e discriminação, propiciando a vivência da sexualidade humana de forma positiva, informada, agradável e segura, baseada na autoestima e no respeito mútuo nas relações sexuais (BRASIL, 2006, p. 37).

Os Parâmetros Curriculares Nacionais (PCN) denominam o termo orientação sexual como um processo formal e sistematizado realizado pela escola, por intervenção pedagógica que tem por finalidade informar e problematizar questões relacionadas à sexualidade, para que os alunos possam desenvolver e exercer sua sexualidade com prazer e responsabilidade (BRASIL, 1997, p. 292).

O modo como os educadores discutem a sexualidade no cotidiano escolar é resultante de como a compreendem. No encontro com o corpo docente ficou claro que eles entendem a sexualidade humana como parte integrante e indissociável do processo de adolescer, manifestadas nas alterações corporais e grupais que levam o adolescente à busca do prazer e das emoções. Embora demonstrem um saber sobre a importância do tema para a comunidade escolar, a maioria relatou ter muitas dificuldades em abordá-lo em sala de 
aula. A falta de conhecimento, insegurança e crença religiosa foram alguns dos argumentos para justificar a abstenção. Então, como pensar questões de sexualidade e saúde sexual e reprodutiva num espaço escolar em que o corpo docente não se sente preparado para trabalhar esses conceitos?

A escola possui um discurso que detém com suas hierarquias devidamente esquematizadas, o tempo e o espaço físico. Nesse sentido, as técnicas que as escolas exercem são de suma importância porque elas definirão o investimento político do corpo (FOUCAULT, 2009). O professor não precisa ser especialista em educação sexual, mas sim ter conhecimentos teóricos da sexualidade para ser capaz de refletir sobre eles a transversalidade, ou seja, a sexualidade num processo pedagógico cujo objetivo é problematizar questões relacionadas, enfocando as várias dimensões que a permeiam, com estratégias de ensino-aprendizagem que facilitem a discussão do tema e favoreçam a participação ativa do adolescente em todo o processo, instigando um posicionamento político contra a patologização e medicalização da diversidade de formas de estar no mundo.

Para Moisez (2010), as Diretrizes Curriculares Nacionais salientam que a orientação sexual não seja discutida em forma de disciplina obrigatória, mas sim uma temática a ser transversal nos diversos conteúdos, sendo aprofundada em cada novo momento em que ela surgir. Diante do exposto, urge a ampliação dos modos de compreensão da sexualidade a áreas afins pata que as expressões de aceitação e direito ao exercício saudável e prazeroso da sexualidade seja protegido de imposições, abusos ou sujeições que possam vir de docentes, gestores escolares, familiares, ou autoridades que utilizem o abuso etário para lhes impor modelos culturais que venham a oprimir seu desenvolvimento sexual pleno.

Portanto, para que o educador em sala de aula efetive seu trabalho em orientar seus alunos, abordando essa temática, é necessário que esse educador supere suas dificuldades individuais, para que consiga orientar de maneira adequada, respeitando suas crenças e valores e contribua para o aprimoramento do debate e 
relevância do papel escolar na sexualidade e saúde sexual e reprodutiva dos estudantes.

\section{Acontecimento 3: a regulação do corpo feminino ou onde está a protagonista?}

O principal motivo pelo qual fomos acionados pela escola para fazermos a intervenção sobre sexualidade e saúde sexual e reprodutiva foi o fato de uma adolescente ter mantido relações sexuais com outros dois alunos no banheiro da escola. Ao perguntarmos onde estava a referida aluna, foi respondido que ela havia saído da escola e mudado de cidade, "foi morar com os avós em um sítio no Sul de Minas Gerais", respondeu a inspetora de alunos. - E os garotos? "São aqueles dois ali", respondeu prontamente, apontando para dois jovens que sorridentes acenaram para nós.

Essa cena implica na constatação de que a adolescente foi punida múltiplas vezes: abandonou ou foi convidada a deixar a escola (?), mudou de cidade, foi afastada de todo seu contexto de sociabilidade e invisibilizada pelo exílio num sítio. Já os garotos estavam ali, marcando o lugar da presença e ilesos em suas masculinidades. Para Louro:

A escola delimita espaços. Servindo-se de símbolos e códigos, ela afirma o que cada um pode (ou não pode) fazer, ela separa e institui. Informa o "lugar" dos pequenos e dos grandes, dos meninos e das meninas. Através de seus quadros, crucifixos, santas ou esculturas, aponta aqueles/as que deverão ser modelos e permite, também, que os sujeitos se reconheçam (ou não) nesses modelos. O prédio escolar informa a todos/as sua razão de existir. Suas marcas, seus símbolos e arranjos arquitetônicos "fazem sentido", instituem múltiplos sentidos, constituem distintos sujeitos (LOURO, 1997, p. 58).

Segundo Laqueur (2001), a realidade e o cotidiano da diferença sexual, que se configura pela sujeição de umas e dominação de outros, são sempre construídas por um discurso fundante que legitima e arraiga numa diferença de natureza e oposição entre atividade doméstica e atividade pública, entre função reprodutora e 
trabalho produtivo, entre o lar e a roça. Já para Perrot (2005), existe uma segregação social dos espaços, e embora as mulheres tenham se apropriado progressivamente de campos de trabalho, rompendo com determinados limites impostos à ordem social e desenvolvendo uma "consciência de gênero", a cidade se constitui como um espaço social, étnico e sexuado, que demarca o espaço público como masculino e o privado como feminino.

Para Foucault (2007), nada há por trás das cortinas, nem sob o chão que pisamos. O que existe são enunciados e relações de poder, que o próprio discurso põe em funcionamento. Dado que os discursos estão localizados entre relações de poder, analisar o discurso sobre sexualidade e saúde sexual e reprodutiva no espaço escolar, seria dar conta da sociedade disciplinar, que discursiva e socialmente invisibiliza e pune as mulheres. Para Foucault (2009), o poder não tem um início definido, como também não tem um fim. Ele se modifica e se transforma ao longo do tempo, se ressignificando e se cristaliza nas instâncias sociais.

A sociedade disciplinar se instaura a partir do início do século XVIII, compreendendo todos os dispositivos que regulam hábitos e comportamentos. Centradas no corpo, objetivava assegurar a obediência às instituições disciplinares que organizam o campo social. As tecnologias disciplinares se destinavam a todos os sistemas de vigilância ou instituições disciplinares: a prisão, a fábrica, o asilo, o hospital, a escola, entre outras (FOUCAULT, 2009).

Em Vigiar e Punir (2009a), o autor expõe o funcionamento do Panoptikon, estrutura arquitetônica idealizada pelo filósofo e jurista inglês Jeremy Bentham (1748-1832), para simbolizar o poder disciplinar. Segundo Foucault (2009a, p. 167), “o panóptico é uma máquina maravilhosa que, a partir dos desejos mais diversos, fabrica efeitos homogêneos de poder". O panóptico é o dispositivo que melhor caracteriza o poder disciplinar, posto ser ele pensado como um sistema arquitetônico constituído de uma torre central e um anel periférico que permite a quem se posiciona no centro visualizar tudo e a todos sem que seja visto. Isso faz que aqueles 
que são vigiados tenham sempre a sensação de que estão sendo observados, de modo que se pode chegar ao momento em que a consciência da vigilância faz que seja desnecessária uma vigilância extensa e objetiva.

Como já vimos, no âmbito da sexualidade, a regulação do corpo feminino foi uma das peças primordiais da estratégia de poder que se anunciou na modernidade, pois foi por meio dessas estratégias que o corpo da mulher foi qualificado, analisado, desqualificado e a sexualidade feminina confiscada e direcionada para o campo da medicina, cuja responsabilidade primordial era apenas reprodutiva (FOUCAULT, 1988).

A partir dessa compreensão, podemos dizer que o espaço escolar, com sua estrutura panóptica contemporânea, reproduz e utiliza os discursos médicos, higienistas e psiquiátricos do século XIX, constituídos num modelo de sexualidade feminina que institui a norma no papel da esposa, de mãe e dona de casa, viabilizando um processo de domesticação e disciplinamento dos comportamentos femininos.

O poder disciplinar entra em cena tendo como função adestrar, assujeitar tais comportamentos para o bem da sociedade. Ao ser flagrada pelo dispositivo panóptico, a estudante foi punida pelo poder disciplinar escolar, para o qual o corpo e a sexualidade feminina são objetos de saberes e poderes mais articulados, que formatam os corpos femininos por meio de normas que se materialializam pela repetição de discursos e normas o lugar da rejeição e da negação da vivência de uma sexualidade feminina livre e plena. Mas apesar desses processos de sujeição, ainda é possível produzir modos ético-estéticos de existência, criando-se meios de driblar os efeitos das normas, das injúrias, da moral, do sexismo. A garota fez isso ao manter relações sexuais dentro do espaço escolar, mesmo com o risco de ser descoberta.

Infelizmente, a exclusão da aluna do espaço escolar e até a privação de estar junto de seus pais confirmam que, apesar da docência de primeiro e segundo grau serem atividades predomi- 
nantemente femininas, o pensamento presente no espaço escolar é hegemonicamente machista e patriarcal e embora a igualdade esteja colocada juridicamente desde muitos anos atrás, ainda vivemos em um mundo em que não existem igualdades de oportunidades para mulheres e homens, principalmente no que diz respeito à liberdade sexual. Ao agirem de forma omissa em relação à situação de abandono escolar pela garota, a escola perde uma oportunidade de lidar com temas inadequados e violentos em relação aos contatos físicos não voluntários entre adolescentes, nos quais os garotos se impõem sobre as garotas sem que ocorram intervenções de educadores.

Nesse caso, ao banalizarem tanto a exclusão da garota, quanto a permanência dos garotos no espaço escolar, a ação educacional deveria intervir na tentativa de restringir a violência de gênero e conceituar novos valores de respeito e trato entre os sexos e gêneros. Entretanto, percebemos que a cultura escolar vigente é a continuidade da cultura de violência de gênero, onde ocorre a promoção da masculinidade perante o feminino, reforçando a possibilidade de uma futura condição adulta passível de manifestações de desigualdade e até de violência física e sexual contra as mulheres, vistas como "objetos" e ao dispor da ação masculina (SAFIOTTI, 2004).

\section{Para não finalizar}

O espaço escolar pode ser um espaço protetivo para os adolescentes, mesmo em contextos sociais de maior vulnerabilidade, possibilitando a construção de conceitos sobre o mundo e acerca de questões da vida cotidiana que visam diminuir as desigualdades. Neste relato, foi possível perceber que mudanças de padrões morais, sociais e culturais não ocorrem em curto espaço de tempo.

Embora existam políticas educacionais e de saúde que deem suporte técnico para o desenvolvimento a atividades que coloquem em evidência a saúde sexual e reprodutiva na escola, os docentes não se sentem à vontade e/ou responsáveis pelo desenvolvimento da temática, pois não encontram garantias de supervisão, formação e de 
coerência teórica e metodológica para que essa prática não entre em conflito com os objetivos dos documentos propostos pelo Estado.

As buscas por ações em relação ao tema surgem apenas quando as manifestações da sexualidade rompem com os princípios morais de prática socialmente aceita, justificando assim intervenções de perspectivas que tragam de volta a normalidade no espaço escolar, a partir de diretrizes moralizantes e medicalizadoras via prevenção de Infecções Sexualmente Transmissíveis que não levam em conta as múltiplas questões embutidas nesses atos.

A partir da análise dos três acontecimentos, percebe-se que, a despeito das diretrizes e das políticas vigentes na área da educação, prevalecem discursos e ações calcadas em preceitos justificados pela moralidade instaurada na sociedade que, via de regra deslegitimam, inviabilizam, cerceiam a expressão da sexualidade feminina, impondo que manifestações da sexualidade fora da norma sejam tolhidas, readequadas ou banidas.

Podemos destacar como ponto de grande relevância a necessidade de incluir a família no processo de orientação sobre saúde sexual e reprodutiva, para que evitem situações como o abandono da escola, por exemplo. O fato de a garota ser "expulsa" do espaço escolar reforça a importância de fomentar a autonomia das mulheres no sentido de que estas decidam sobre seu corpo, seus desejos e suas necessidades e conveniências. A partir da possibilidade de decidir a respeito daquilo que é mais adequado para sua vida, as práticas de cerceamento de sua liberdade vão se descontruindo - pela via do conhecimento e da informação - de modo a construir-se uma perspectiva em que a mulher não é mais percebida em espaço algum como um ser submisso ou inferior em relação ao homem, ou seja, Estado, família, sociedade e dogmas religiosos não podem decidir acerca do que será melhor para cada uma.

O papel do docente seria auxiliar seus alunos, promovendo discussão, apresentando caminhos para que se encontrem "soluções”, de maneira dinâmica e construtiva, mas nunca esquecendo que cada indivíduo possui suas especificidades. Todavia, ao ressaltar 
a sexualidade como um processo de construção cultural e histórica, é perceptível que as escolas ainda têm carência de profissionais capacitados para lidar com tal realidade, pois, mesmo com todo o avanço, há desafios a serem resolvidos para que a educação sexual seja vista como importante e indispensável, pois esta é inerente na vida de todos os sujeitos.

A partir das narrativas e observações construídas no percurso cartográfico, pudemos dar alguma visibilidade política e teórica aos processos de subjetivação e vivências da sexualidade no espaço escolar. Vimos que o machismo e a própria experiência de ser mulher não se limitam a um simples sentimento ou ação redutível ao indivíduo, mas é efeito de complexas produções discursivas que objetivam a gestão, seja do homem-corpo, dos planos moleculares; seja do homem-espécie, dos planos molares que constituem as populações. Nesse sentido, a discriminação e preconceitos instituídos acerca da sexualidade feminina - quando esta foge do âmbito reprodutivo - se materializam a partir de práticas discursivas que circulam por entre territórios e constituem os sujeitos a partir da delimitação de relações de poder, além de instituir modos de subjetivação hegemônicos.

A sexualidade está presente no espaço escolar porque ela faz parte da vida, dos sujeitos e dos processos socioculturais, não sendo passível de descarte, ou seja, a presença da sexualidade no ambiente escolar independe da inclusão ou não desses assuntos nos regimentos escolares. Talvez, o maior desafio a ser enfrentado quando se lida com questões de sexualidade e saúde sexual e reprodutiva na escola seja a necessidade de o corpo docente se reconstruir, romper com seus próprios paradigmas e, como um educador, garantir o respeito e a compreensão relativos à diversidade de valores, crenças, condições e escolhas de outrem para além e aquém de suas escolhas pessoais. 


\section{Referências}

BRASIL. Estatuto da Criança e do Adolescente. Brasília: Ministério da Justiça, 1990. Disponível em: < http://www.planalto.gov.br/ccivil 03/leis/18069.htm>

BRASIL. Secretaria de Educação Fundamental. Parâmetros Curricular Parâmetros Curriculares Nacionais: Orientação sexual. Brasília: Ministério da Educação, 1997.

BRASIL. Direitos Sexuais e Direitos Reprodutivos: uma prioridade do governo/Ministério da Saúde, Secretaria de Atenção à Saúde, Departamento de Ações Programáticas Estratégicas - Brasília: Ministério da Saúde, 2005 Disponível em: $<\underline{\text { http://bvsms.saude.gov.br/bvs/publicacoes/cartilha direitos sexuais repro- }}$ dutivos.pdf $>$

BRASIL. Ministério da Saúde. Secretaria de Atenção à Saúde. Marco teórico e referencial: saúde sexual e saúde reprodutiva de adolescentes e jovens. Brasília: Ministério da Saúde, 2006.

BUSIN, Valéria Melki. Religião, sexualidades e gênero. Rever, Ano 11, n. 1, jan./ jun. 2011.

DELEUZE, G. e GUATTARI, F. Mil Platôs: capitalismo e esquizofrenia 2, v. 1. São Paulo: Ed. 34, 2011.

DOMINGOS, Marília de F. N. Escola e laicidade. O modelo francês, Interacõoes cultura e Comunidade, v. 3, n. 4. Uberlândia: Universidade Católica, 2008.

FOUCAULT, Michel. História da sexualidade 2: O uso dos prazeres. Rio de Janeiro: Graal, 1984.

FOUCAULT, Michel. História da Sexualidade I: a vontade de saber. Rio de Janeiro: Graal, 1988.

FOUCAULT, Michel. A Ordem do Discurso. São Paulo: Loyola, 2007.

FOUCAULT, Michel. A arqueologia do saber. Tradução de Luiz Felipe Baeta Neves, 7. ed. Rio de Janeiro: Forense Universitária, 2008.

FOUCAULT, Michel. Microfísica do poder, 4. ed. Rio de Janeiro: Graal, 2009.

FOUCAULT, Michel. Vigiar e Punir. Petrópolis: Vozes, 2009a. 
FRANCA, Inacia Sátiro Xavier de; BAPTISTA, Rosilene Santos. A construção cultural da sexualidade brasileira: implicações para a enfermagem. Rev. bras. enferm. Brasília, v. 60, n. 2, p. 202-206, abr. 2007. Disponível em: http://www. scielo.br/scielo.php? script $=$ sci arttext\&pid $=$ S003471672007000200014\&ln$\mathrm{g}=$ en\&nrm $=$ iso.

GUATTARI, Félix. Caosmose: Um novo paradigma estético. Tradução: Ana Lúcia de Oliveira e Lúcia Cláudia. São Paulo: Editora 34, 1992.

GUATTARI, Félix. \& ROLNIK, Suely. Micropolítica: cartografias do desejo. Petrópolis, RJ: Vozes, 1986.

HASHIZUME, Cristina Miyuki; TELLES JR., Hamilton de Oliveira Telles. A cartografia como epistemologia da compreensão: Pensando o processo de implementação de classes hospitalares a partir do olhar da Psicologia e da Educação. In: Anais IV Seminário Brasil-Colômbia de Estudos e Práticas de Compreensão | II Colóquio Internacional do Grupo de Estudos Literários (GEL). São Paulo: Universidade Metodista de São Paulo, 11-14 nov. 2019.

KASTRUP, Virgínia. O funcionamento da atenção no trabalho do cartógrafo. In: PASSOS, Eduardo; KASTRUP, Virgínia; DA ESCÓSSIA, Liliana (Org.). Pistas do método da cartografia. Pesquisa-intervenção e produção de subjetividade. Porto Alegre: Sulina, 2009.

LAQUEUR, Thomas. Inventando o Sexo: Corpo e gênero dos gregos à Freud. Rio de Janeiro: Relume Dumará, 2001.

LOURO, Guacira Lopes. Gênero, sexualidade e educação. Uma perspectiva pós estruturalista. Petrópolis, RJ: Vozes, 1997.

LOURO, Guacira Lopes. O corpo educado: pedagogias da sexualidade. Belo Horizonte: Autêntica, 2010.

MAIA, Ana Cláudia Bortolozzi, SPAZIANI, Raquel Baptista. Manifestações da sexualidade infantil: percepção de pais e professoras de crianças de 0 a 6 anos. Rev Linhas. 2010; 11 (1): 68-84 [acesso em: 12 out. 2016]. Disponível em: http:// www.revistas.udesc.br/index.php/linhas/article/view/2017/pdf 43.

MOIZES JS, BUENO SMV. Compreensão sobre sexualidade e sexo nas escolas segundo professores do ensino fundamental. Rev Esc Enferm USP. 2010; 44 (1): 205-12. 
PASSOS, Eduardo \& BENEVIDES, Regina. Por uma política da narratividade. In: PASSOS, Eduardo; KASTRUP, Virgínia; DA ESCÓSSIA, Liliana (Org.). Pistas do método da cartografia. Pesquisa-intervenção e produção de subjetividade. Porto Alegre: Sulina, 2009.

PAULA, Paulo Sergio Rodrigues de. Barebacking sex: a roleta russa da Aids? Rio de Janeiro: Multifoco, 2010.

PERROT, Michelle. Minha história das mulheres. São Paulo: Editora Contexto, 2007.

ROMERO, Kelencristina T. et al. O conhecimento das adolescentes sobre questões relacionadas ao sexo. Rev. Assoc. Med. Bras. São Paulo, v. 53, n. 1, p. 1419, fev. 2007.

SAFIOTTI, Helieth. Gênero, patriarcado, violência. São Paulo: Fundação Perseu Abramo, 2004, 151 p. Disponível em: http://bases.bireme.br/cgi-bin/ xislind.exe/iah/online/?IsisScript=iah/iah.xis\&src=google \&base=LILACS\&lan$\mathrm{g}=\mathrm{p} \&$ nextAction $=\operatorname{lnk} \& \operatorname{exprSearch}=622$ 256\&indexSearch=ID.

VANDRESEN. Daniel Salésio. Uma análise do discurso e do não-discursivo na arqueologia de Michel Foucault. Aurora, Marília, v. 7, n. 2, p. 79-92, jan./ jun. 2014.

WORLD HEALTH ORGANIZATION. Sexual health. Switzerland: WHO, 2007. 